\section{Amniotic membrane in ophthalmology: indications and limitations limitations}

${ }^{1}$ Division of Ophthalmology and Visual Sciences, Queens Medical Centre, University of Nottingham,

Nottingham, UK

${ }^{2}$ Research Institute of Ophthalmology, Cairo, Egypt

Correspondence: HS Dua, Division of Ophthalmology, B Floor,

Eye ENT Centre,

Queens Medical Centre, Derby Road,

Nottingham NG7 2UH, UK

Tel: + 01159249924

ext 61796;

Fax: +0161272 6618;

E-mail: Harminder.dua@

nottingham.ac.uk

Received: 25 November 2008

Accepted: 30 November 2008

Published online: 23 January 2009

Financial interest: None.

\begin{abstract}
The amniotic membrane remains a useful tool in the treatment of several ophthalmic conditions, especially those related to the ocular surface. However, the 'success' reported in individual case reports and case series is not substantiated in the few published randomised controlled trials. More often than not, it is not as good as existing alternative options and, at best, is as good but with probably an increased cost. The variable outcomes could be related to inter and intra donor variations in the membrane and the depletion or alterations in its constituents subsequent to processing and storage. The membrane thus is a fairly 'non-standardised product' making comparisons of different applications and indications difficult. The potential for 'epidemic' infections, such as HIV, hepatitis B and C, is a serious issue as, in many parts of the world, fresh unquarantined membrane, at times with no tests for the above infectious agents, is being used. The exact mechanism of action of the membrane is not known but the consensus is that it acts as a substrate or scaffold for host cells to populate and thus facilitate healing and repair. The development of a standard 'synthetic membrane' using collagen or polymer matrices impregnated with putative beneficial ingredients, such as growth factors and antimicrobials, is being considered and may prove to be a step in the right direction. Eye (2009) 23, 1954-1961; doi:10.1038/eye.2008.410; published online 23 January 2009
\end{abstract}

Keywords: amniotic membrane; indications; limitations

\section{Introduction}

The amniotic membrane (AM) is the inner avascular layer of the three-layered foetal membrane. The first therapeutic use of AM was successfully achieved by Davis ${ }^{1}$ in 1910 for skin transplantation. Subsequently, the first ocular indication for AM was suggested by de Rotth ${ }^{2}$ in 1940 following successful treatment of a chemical burn of the ocular surface. Although use of the membrane for ocular indications continued in the Soviet Union, ${ }^{3}$ it was not until Juan Batlle's report in 1992 that it re-emerged as an important modality of treatment. As of 25 September 2008, there are over 700 peerreviewed publications (Table 1) for the ocular use of AM highlighting novel increasing indications and therapeutic applications.

The structure of the membrane, which presents a single layer of metabolically very active cuboidal to columnar epithelium firmly attached to a basement membrane and an avascular and relatively sparsely populated stroma, makes it an easy-to-handle and resilient tissue. ${ }^{4,5}$ The epithelium and stroma are endowed with a number of cytokines and growth factors, key among which are transforming growth factor $\beta^{6}$ and epidermal growth factor. ${ }^{7}$

The exact mechanism of action is not clearly defined but in most instances it is widely accepted to act as a substrate, which is very conducive to epithelial cell migration and attachment. Its biological constituents as mentioned above are also invoked as contributing to its beneficial effects.

Two important methods of processing and preservation of the membrane are in vogue. One uses freezing of cleaned fresh membrane at $-80{ }^{\circ} \mathrm{C}$ in either phosphate-buffered saline in dimethylsulphoxide (PBS DMSO) ${ }^{8}$ or in Eagle's Minimum Essential Medium (MEM) with glycerol. ${ }^{9}$ The second method employs freeze drying of the membrane and rehydration before use. Fresh unpreserved membrane is also used quite commonly in the developing world but not in the Western countries where strict 
Table 1 To show the increasing number of peer reviewed publications relating to the ocular use of amniotic membrane

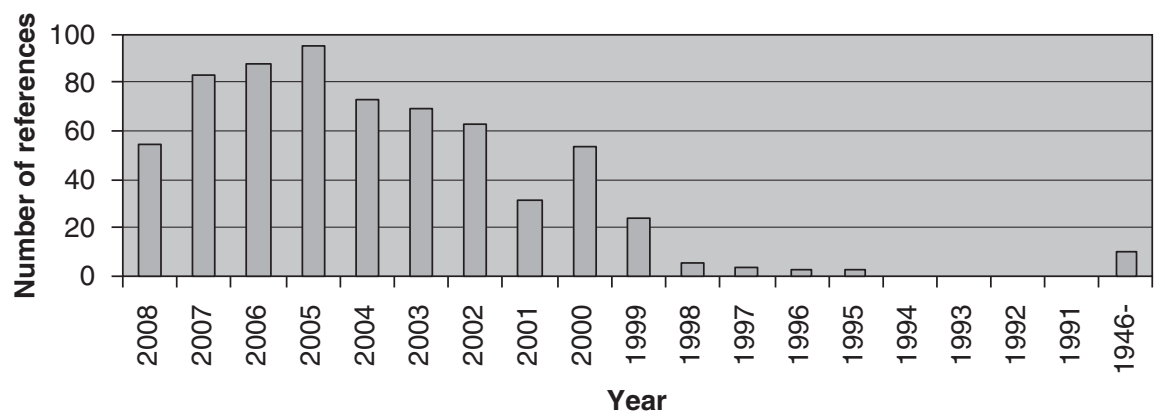

For the year 2008, the figure represents publications until 25th of September.

legislation stipulates HIV, hepatitis B, C, and HTLV tests on the donor serum at the time of procuring the membrane and the HIV test repeated 6 months later to cover the window period. ${ }^{10}$ For this the membrane is quarantined for 6 months.

\section{Clinical applications}

\section{Ocular surface reconstruction}

When used for ocular surface reconstruction, there are three basic principles that govern the manner in which the membrane is applied to the eye.

(1) Graft or inlay technique. The AM is intended to act as a substrate or scaffold for epithelial cells to grow and is therefore incorporated into the host tissue (cornea or conjunctiva). The AM is usually placed basement membrane side up.

(2) Patch or overlay technique. Here the AM functions essentially as a cover or a biological bandage 'contact lens,' protecting the underlying healing epithelial surface. The intention is for the membrane to fall off or be removed over a period of time.

(3) Layered or fill in technique. In this scenario, the AM is used in multiple small pieces to fill the entire depth of a corneal ulcer or crater. A relatively larger 'graft' of membrane is applied to the surface over which the epithelium is expected to grow.

In situations 1 and 3, keratocytes have been shown to re-populate the amnion stroma, thus building corneal stromal tissue (by Said DG et al, paper under revision, Ophthalmology).

\section{Cornea}

Limbal stem cell deficiency

Acute or chronic limbal stem cell loss constitutes a major indication for the use of AM. Common causes include cicatrising diseases such as Stevens-Johnson syndrome, chemical or thermal burns, and ocular cicatricial pemphigoid (OCP). In such cases AM transplantation is performed in conjunction with stem cell transplantation. Tsubota et $a l^{11}$ has been credited with the first applications of AM in OCP, with success in 9 of 11 patients presented. In cases of partial limbal stem cell deficiency, Sangwan et $a l^{12}$ documented successful outcomes in four patients treated with AM following pannus resection. In total limbal stem cell deficiency, the successful outcomes were achieved in $60-70 \%$ of patients. When conjunctival involvement is extensive, the success rate is largely dependent on the underlying pathology of the cicatrising disease. The prognosis is worse when there is progressive cicatrisation (as with Stevens-Johnson syndrome and ocular cicatricial pemphigoid) compared with 'burnt out' or long-standing cicatrisation as after chemical burns.

When limbal stem cell deficiency is partial with conjunctivalisation of the cornea associated with mild vascularisation, sequential sector conjunctival epitheliectomy ${ }^{13}$ can provide a good outcome even without use of the membrane.

\section{Pseudophakic bullous keratopathy}

Pires et $a^{14}$ described the use of AM in the treatment of bullous keratopathy (Figure 1). In their group of 55 patients, 50 patients remained pain-free after 33 weeks following epithelial debridement and replacement with an AMT. Espana et al $^{15}$ reported on 18 patients with a mean followup of 25 months and concluded that $88 \%$ achieved painfree status. Anterior stromal puncture is an effective alternative method for managing this condition.

Persistent corneal epithelial defects and perforations Amniotic membrane has been successfully used in the treatment of persistent epithelial defects and perforations since the mid-to-late 1990s (Figure 2). Azuro-Blanco et $a l^{16}$ reported the success of AMT in promoting 

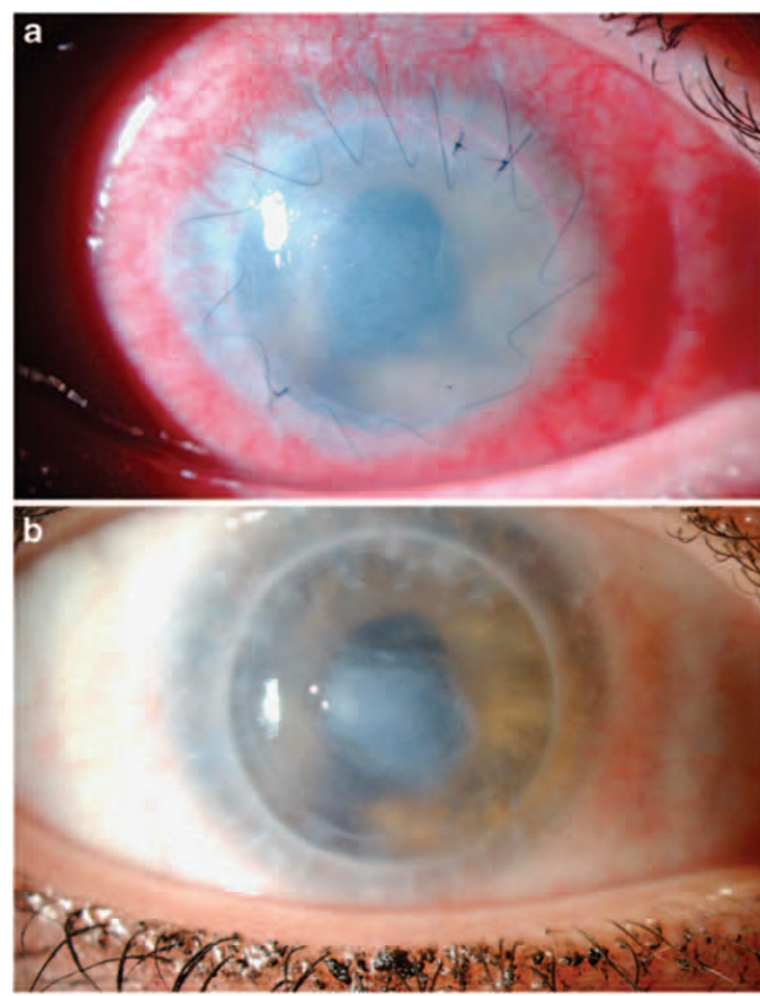

Figure 1 (a) An eye with bullous keratopathy in a failed penetrating corneal graft treated with an amniotic membrane graft (inlay). The $10 \mathrm{~mm}$ disc of membrane is sutured in place with a running $10^{\prime} \mathrm{O}$ nylon suture. The sutures were removed at 1-week post-operation. (b) The same eye 10 months later. The bullous keratopathy has settled but the membrane has retracted to an opalescent mass in the centre of the cornea.

epithelialisation, if the stroma was not severely thinned. Kruse et $a l^{17}$ described the use of AMT as a possible space filler in this setting to increase stromal thickness by placing the AM one above the other, either with conventional sutures or fibrin glue. ${ }^{18}$ However, the early detachment of the membrane despite diligent suturing remains a limiting factor with its use. ${ }^{19} \mathrm{Su}$ and $\mathrm{Lin}^{20}$ have described the use of the AM to successfully seal corneal perforations. Fibrin or cyanoacrylate glue application are other effective alternative means of sealing perforations.

\section{Conjunctival reconstruction}

\section{Pterygium}

Prabhasawant et $a l^{21}$ described the use of AM as an adjunct in the surgical treatment of pterygium, as an alternative to autologous conjunctival graft. To date, over 85 peer-reviewed publications can be found related to AMT for this indication. The results of this technique have been controversial with suggestions of higher recurrence rates described. These will be described in more detail under limitations (see below).
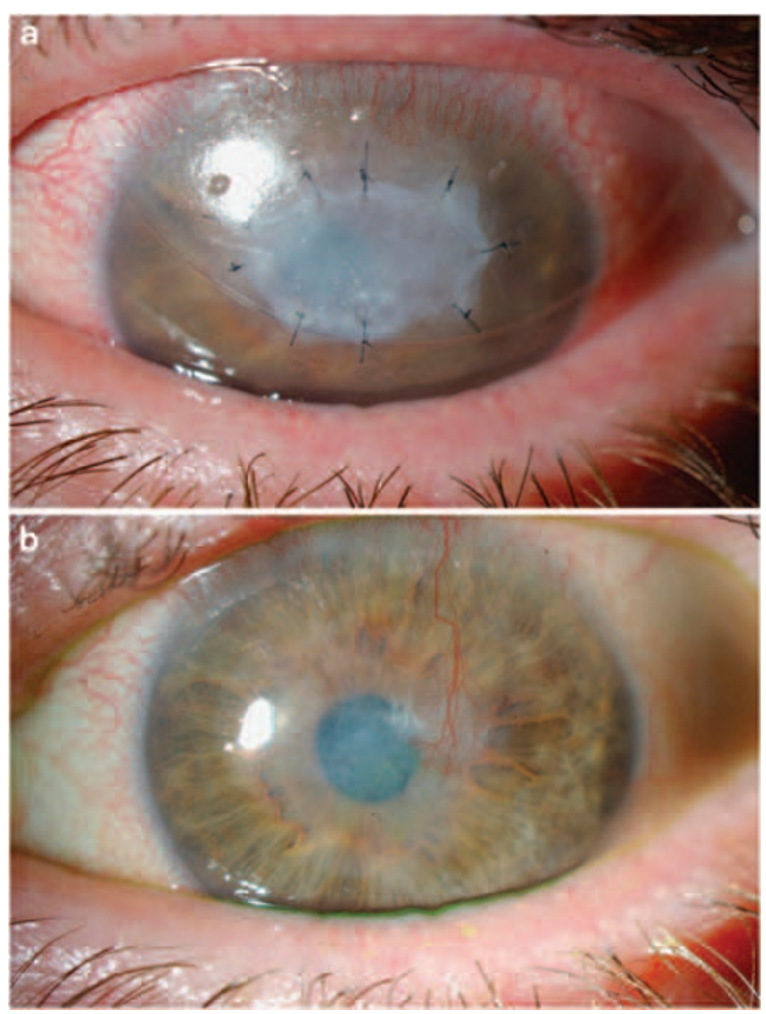

Figure 2 (a) Showing the use of amniotic membrane for a persistent epithelial defect. (b) The same eye, 8 months following incorporation of the amniotic membrane into the cornea. Note that active vascularisation has occurred despite use of membrane but the defect healed successfully.

\section{Tumours}

The amniotic membrane has been used in the management of both conjunctival and corneal tumours following surgical resection (Figure 3). Dalla Pozza et al ${ }^{22}$ described the successful treatment of conjunctival melanoma with adjuvant use of AM describing rapid initial healing of the defect followed by long-term surface stability. In a similar study, Gunduz et $a l^{23}$ reported complications of symblepharon formation and partial stem cell deficiency, following resection and reconstruction with AM in 10 patients with ocular surface neoplasms.

\section{Symblepharon}

The AM has been used in the prevention of symblepharon and its treatment. Solomon et $a l^{24}$ described a $71 \%$ success rate in forniceal reconstruction in a variety of conditions. Barbabino et $a^{25}$ suggested that AM maybe used for ocular surface reconstruction in OCP. However, the effectiveness deteriorated over time, with $44 \%$ recurrence after 28 weeks.

Often AM can be used as a patch and sutured to the fornices through the eyelids to prevent symblepharon formation in the acute phase of chemical injuries. This 

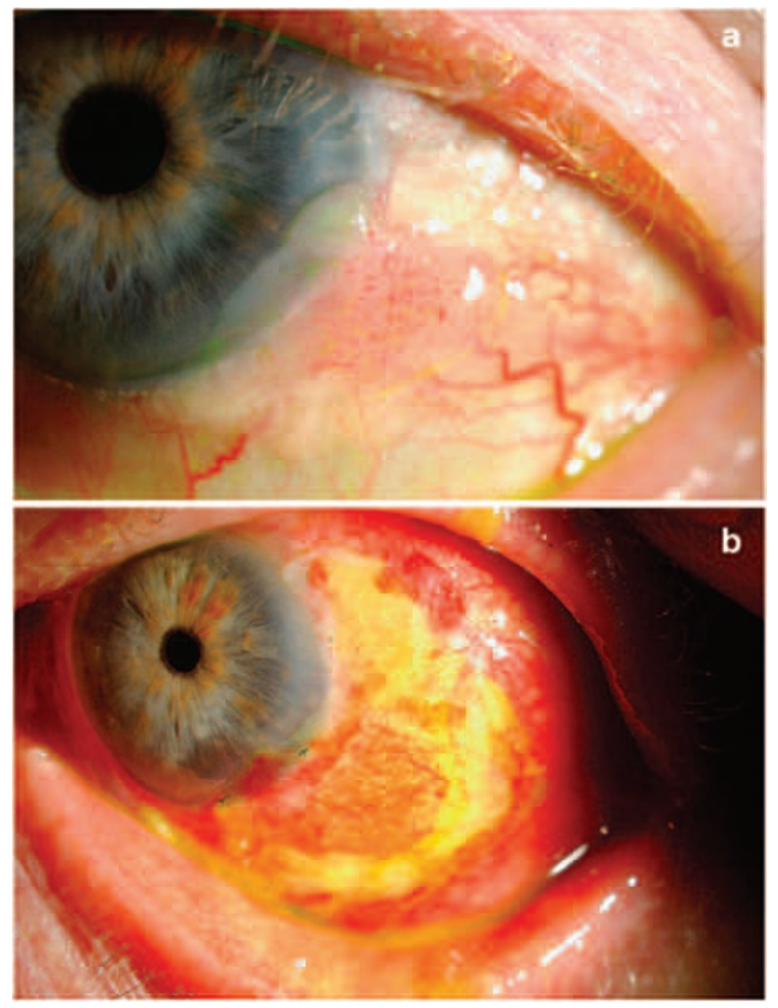

Figure 3 (a) Conjunctival intraepithelial neoplasia (CIN). (b) The same eye following excision and an amniotic membrane cover, 1-week postoperatively.

allows the underlying epithelial defect to heal and maintain fornix architecture. Keirkhah et al ${ }^{26}$ recently reported the use of a sutureless AM patch in acute severe alkali injuries (ProKera ${ }^{\circledR}$; Bio-Tissue Inc., Miami, Florida). For some time, we have used an inexpensive and easily accessible method for this purpose, namely an AM sutured around a conformer, with great success. The patch acts as a bandage and the rigidity of the conformer maintains the fornices until full healing has taken effect (Figure 4). Generally, the AM is replaced every 7-10 days. As mentioned above, the prognosis is worse for progressive cicatrising conjunctival disease (with associated chronic inflammation) than for stable, non-progressive cicatrisation. ${ }^{27}$

\section{Glaucoma}

Similar to its use in symblepharon treatment, AM has been used as an adjunct in glaucoma surgery and as a treatment option in its complications. Its main purpose has been to reduce scarring at the time of filtering surgery, to repair early or late leaks, and act as a cover for valve procedures. The first report by Fugishima $e t a^{28}$ used AM to prevent adhesion of the scleral flap to the overlying conjunctiva. Although, good postoperative intraocular pressure control was achieved in 9 of 13 patients, no long-term data are provided. The use of AMT in late bleb leaks is controversial. Recently, NagaiKusuhara $e a^{29}$ reported good long-term results in patients treated with AMT-assisted bleb revision. They presented six patients with a mean of 15-month followup without complications during this period. However, earlier reports suggested that AMT was not effective in this setting. ${ }^{30}$ The AM has also been successfully used to cover exposed pericardial patch over the tube of Ahmed valves. $^{31}$

\section{Oculoplastics and orbits}

There are limited reports on AM use in oculoplastic and orbital surgery. Most have been aimed at reconstruction of the fornices or as a substrate for epithelialisation of conjunctival defects for prosthetic fitting. Poonyathalang et $a^{32}$ described 10 cases of forniceal reconstruction where socket contraction prevented the fitting of a prosthesis. A total of $80 \%$ achieved successful fitting following reconstruction. A more novel use of the membrane was described by Finger. ${ }^{33}$ Using the AM as a buffer patch between the cornea and radioactive eye plaques for the treatment of ocular surface melanomas, Finger described the amnion as effective in reducing pain and protecting the cornea.

\section{Limitations of AM}

The AM in its early use was portrayed as a potential 'miracle' cure or adjunct for almost every surgical procedure of the external adnexea and ocular surface to heal defects and treat scarring. However, as with all new developments, AM has been tried for multiple indications but only now is starting to find its true niche in ophthalmology. The evidence base for its use remains limited. At the time of writing, over 8876 references were cited on PubMed using 'amniotic membrane' as the keyword. Further refining this search, with the addition of the word 'AND eyes' reduced the number of citations to 730 and further down to 20 when 'amniotic membrane AND eyes AND randomised controlled trails' were used as keywords.

In relation to glaucoma procedures, six randomised controlled trials are reported. Elizier $e t a l^{34}$ compared primary trabeculectomy with and without AM in 32 patients. They concluded that 'results showed no statistically significant difference between groups regarding postoperative intraocular pressure after 1-year follow-up.' More recently, Sheha et $a l^{35}$ described that 'trabeculectomy combined with MMC and AMT compared with trabeculectomy with MMC alone has higher success rates, lower postoperative mean IOPs, and 

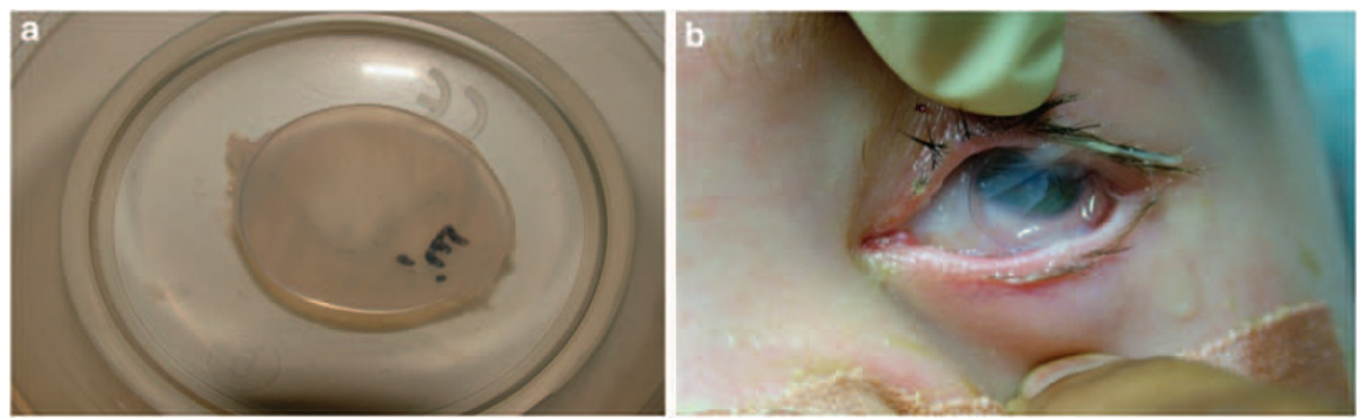

Figure 4 (a) Showing an amniotic membrane covering a conformer shield of size ' $E$ ' in a gallipot. (b) Showing the use of the conformer with amniotic membrane inserted into a patient with Stevens-Johnson syndrome.

less complication rates.' Compared with Elizier et al, ${ }^{34}$ Sheha et $a l^{35}$ recruited high-risk glaucoma patients.

In the treatment of leaking trabeculectomy blebs, Budenz et $a l^{36}$ showed that AMT did 'not offer an effective alternative to conjunctival advancement'. Similarly, Rauscher et $a l^{37}$ offered limited support for AM in this setting stating 'although prone to early releakage, AMT may be a suitable alternative to conjunctival advancement in the long-term.' Liu et $a l^{38}$ described 'no significant benefit' in the use of AM as an adjunct in Molteno tube surgery in corneal transplantation when compared with tube surgery without AMT.

Pterygium removal may go hand-in-hand with aggressive recurrence (Figure 5) unless adequate measures are taken to prevent recurrence at the time of surgery. Luanratanakorn et $\mathrm{al}^{39}$ stated that 'amniotic membrane graft had a higher recurrence rate than conjunctival autograft', confirming an earlier study by Tanauvat and Martin ${ }^{40}$ who showed an 'unacceptably high recurrence rate.' However, Küçükerdönmez et $a l^{41}$ described delayed vascularisation with AMT. Li et al ${ }^{42}$ suggested that the concurrent use of recombinant human epidermal growth factor with AMT following pterygium excision promotes reepithelisation. Unfortunately, no comparison was made to patients without AMT in this setting.

In acute alkali burns, AMT did not convey any benefit in visual improvement. However, there was a reduction in acute pain and more rapid epithelisation in moderate burns. ${ }^{43,44}$ No benefit was confered in severe burns. No difference was found in the treatment of neurotrophic ulcers compared with conventional therapies. ${ }^{45}$

Conversely, some benefit was found in symblepharon and forniceal reconstruction using $\mathrm{AM}^{46}$

Importantly, although the definition of failure maybe straightforward the definition of success following AM use is less clear in published literature. Maharajan et $a l^{27}$ addressed this issue. They pointed out that the definition of success should relate to the purpose of the AM, ie, whether used as a patch (onlay) or a graft (inlay), and outcome of application. The outcome related to success, where the membrane produced the desired objective for which its use was proposed, partial success where the objective was achieved but not necessary related to the intended use of the AM or when not all objectives were achieved. For example, if the membrane used was intended as a graft to close a persistent epithelial defect and it did act as a graft and the defect healed (both purpose and objective were achieved), it was considered an unqualified success. If the membrane used was intended as a graft to close a persistent epithelial defect and it fell off in a couple of days but the defect went on to heal (purpose not achieved but objective achieved), it was considered a partial success. Similarly, when more than one objective was set and not all were achieved, it was still considered a partial success. It was considered a failure when the objective was not achieved irrespective of whether the intended purpose was achieved or not.

In 74 consecutive procedures using AM for different indications, success was achieved in only $22-58 \%$, partial success in $6-34 \%$ and failure in $33-44 \%$. These findings support the viewpoint that poor definition of success and failure in studies may significantly skew the ultimate conclusion in relation to AM use and make it difficult to evaluate its role in various clinical scenarios that AM is being 'successfully' recommended for.

Further, the various inhibitory and proinflammatory cytokines and other molecules identified in AM have contradictory actions. For instance, IL- 6 and IL- 8 are proinflammatory and conversely, IL-10 and IL-1ra are anti-inflammatory, yet both are present in the AM. Similar contradictions of action exist in the role of AM in vascularisation where matrix metalloproteinases (MMPs) promote vascularisation and melts. However, tissue inhibitors of metalloproteinases have the reverse role in inhibiting vascularisation and melts. Again both molecules have been shown to be present within the membrane, and although it is possible that the required components of the membrane for which its use is indicated may play a predominate role and host factors 

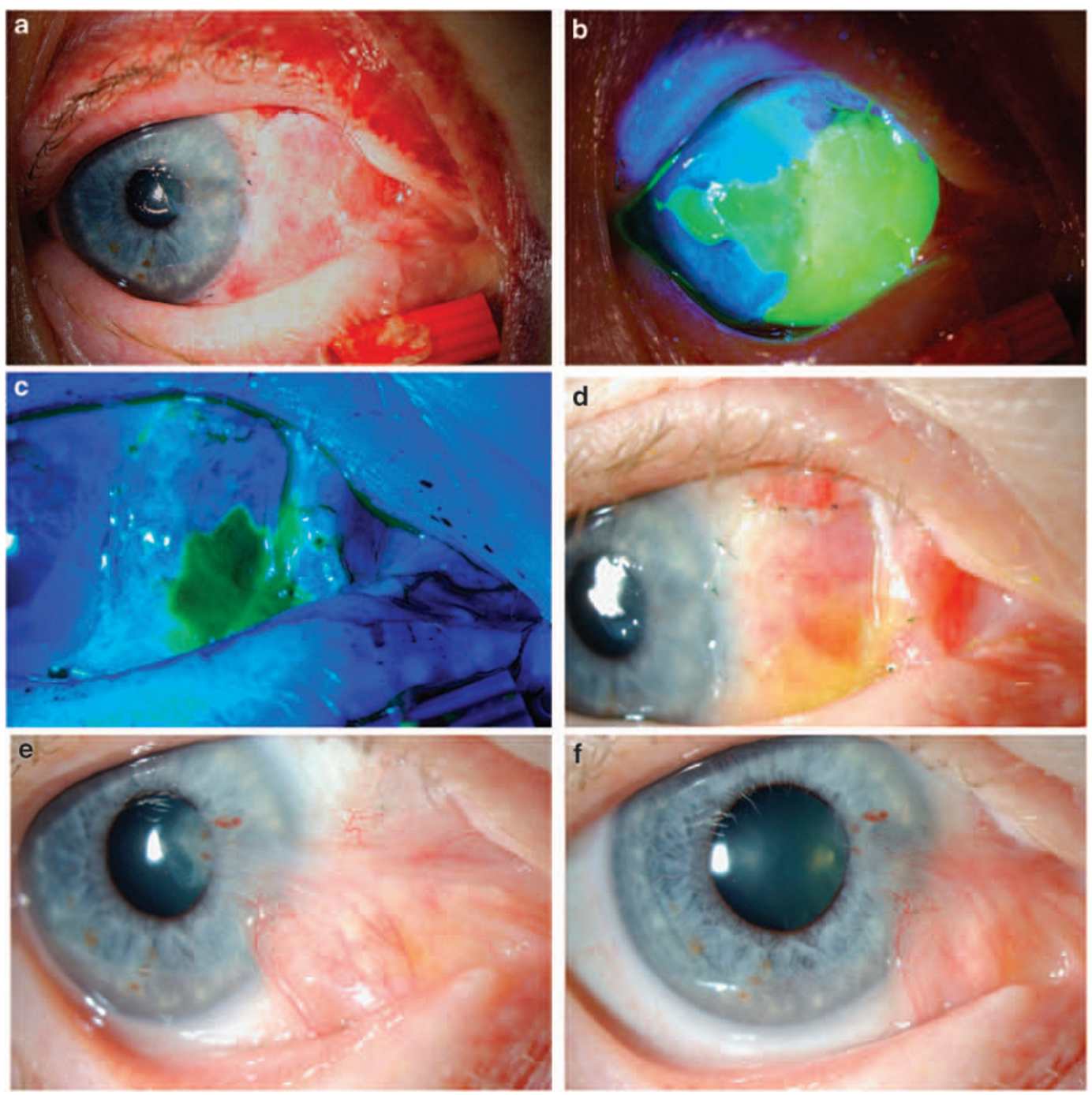

Figure 5 (a) Day 1 post-pterygium excision and amniotic membrane graft. (Slit lamp photomicrograph). (b) Eye as in (a), stained with fluorescein. (c) Showing membrane in place, 12 days post-surgery. Fluorescein-stained image illustrating good epithelisation over the membrane, which is becoming incorporated into the host ocular surface. (e and f) Same eye 6 months later showing recurrence of pterygium despite the use of amniotic membrane.

may limit the less desirable components, it remains difficult to define a specific cascade of events that may, for certain, define the role of the amnion in a given clinical situation.

As with any human tissue, donor variations will affect the composition of the AM to some degree. Inter donor variations are common. These variations reflect the many facets of diversity in a given population. These include patient age, race, maternal health, and diet. Further variations exist dependent on the foetal sex, health, gestational age, and specifics relating to labour. Hopkinson et $a l^{44}$ showed the relationship of handling and processing of AM on the possible eventual alterations in the final make of the AM with regard to $\operatorname{TGF} \beta$. Similar variations have been reported by Gicquel et $a l^{47}$ with regard to epidermal growth factor. The eventual clinical effect of the AM may therefore be enhanced or lost dependent on the handling and processing of the amnion. To date, this process is not standardised for inter and intra donor variations, making subsequent clinical data on indications and outcomes difficult to interpret as the composition of the membrane may vary substantially.

Several laboratories are working towards the generation of a 'synthetic membrane' where collagen or polymers are used as matrices to incorporate growth factors, cytokines, antimicrobial peptides, and other substances tailored towards specific clinical applications. This would pave the way to a standardised product with hopefully predictable outcomes. 


\section{References}

1 Davis JW. Skin transplantation with a review of 550 cases at the Johns Hopkins Hospital. Johns Hopkins Med J 1910; 15: 307.

2 de Rotth A. Plastic repair of conjunctival defects with fetal membranes. Arch Ophthalmol 1940; 23: 522-525.

3 Dua HS, Gomes JA, King AJ, Maharajan VS. The amniotic membrane in ophthalmology. Surv Ophthalmol 2004; 49: 51-77.

4 Bourne GL. The microscopic anatomy of the human amnion and chorion. Am J Obstet Gynecol 1960; 79: 1070-1073.

5 Fukuda K, Chikama T, Nakamura M, Nishida T. Differential distribution of subchains of the basement membrane components type IV collagen and laminin among the amniotic membrane, cornea, and conjunctiva. Cornea 1999; 18: 73-79.

6 Schilling B, Yeh J. Transforming growth factor-beta(1), -beta(2), -beta(3) and their type I and II receptors in human term placenta. Gynecol Obstet Invest 2000; 50: 19-23.

7 Rao CV, Carman Jr FR, Chegini N, Schultz GS. Binding sites for epidermal growth factor in human fetal membranes. J Clin Endocrinol Metab 1984; 58: 1034-1042.

8 Dua HS, Azuara-Blanco A. Amniotic membrane transplantation. Br J Ophthalmol 1999; 83: 748-752.

9 Kim JC, Tseng SCG. Transplantation of preserved human amniotic membrane for surface reconstruction in severely damaged rabbit corneas. Cornea 1995; 14: 473-484.

10 Adds PJ, Hunt CJ, Dart JK. Amniotic membrane grafts, 'fresh' or frozen? A clinical and in vitro comparison. Br J Ophthalmol 2001; 85: 905-907.

11 Tsubota K, Satake Y, Ohyama M. Surgical reconstruction of the ocular surface in advanced ocular cicatricial pemphigoid and Stevens-Johnson syndrome. Am J Ophthalmol 1996; 122: $38-52$.

12 Sangwan VS, Matalia HP, Vemuganti GK, Rao GN. Amniotic membrane transplantation for reconstruction of corneal epithelial surface in cases of partial limbal stem cell deficiency. Indian J Ophthalmol 2004; 52: 281-285.

13 Dua HS. The conjunctiva in corneal epithelial wound healing. Br J Ophthalmol 1998; 82: 1407-1411.

14 Pires RT, Tseng SC, Prabhasawat P. Amniotic membrane transplantation for symptomatic bullous keratopathy. Arch Ophthalmol 1999; 117: 1291-1297.

15 Espana EM, Grueterich M, Sandoval H, Solomon A, Alfonso E, Karp CL et al. Amniotic membrane transplantation for bullous keratopathy in eyes with poor visual potential. J Cataract Refract Surg 2003; 29: 279-284.

16 Azuara-Blanco A, Pillai CT, Dua HS. Amniotic membrane transplantation for ocular surface reconstruction. $\mathrm{Br} \mathrm{J}$ Ophthalmol 1999; 83: 399-402.

17 Kruse FE, Rohrschneider K, Volcker HE. Multilayer amniotic membrane transplantation for reconstruction of deep corneal ulcers. Ophthalmology 1999; 106: 1504-1510.

18 Hick S, Demers PE, Brunette I, La C, Mabon M, Duchesne B. Amniotic membrane transplantation and fibrin glue in the management of corneal ulcers and perforations: a review of 33 cases. Cornea 2005; 24: 369-377.

19 Letko E, Stechschulte SU, Kenyon KR, Sadeq N, Romero TR, Samson CM et al. Amniotic membrane inlay and overlay grafting for corneal epithelial defects and stromal ulcers. Arch Ophthalmol 2001; 119: 659-663.
20 Su CY, Lin CP. Combined use of an amniotic membrane and tissue adhesive in treating corneal perforation: a case report. Ophthalmic Surg Lasers 2000; 31: 151-154.

21 Prabhasawat P, Barton K, Burkett G, Tseng SC. Comparison of conjunctival autografts, amniotic membrane grafts, and primary closure for pterygium excision. Ophthalmology 1997; 104: 974-985.

22 Dalla Pozza G, Ghirlando A, Busato F, Midena E. Reconstruction of conjunctiva with amniotic membrane after excision of large conjunctival melanoma: a long-term study. Eur J Ophthalmol 2005; 15: 446-450.

23 Gunduz K, Ucakhan OO, Kanpolat A, Günalp I. Nonpreserved human amniotic membrane transplantation for conjunctival reconstruction after excision of extensive ocular surface neoplasia. Eye 2006; 20: 351-357.

24 Solomon A, Espana EM, Tseng SCG. Amniotic membrane transplantation for reconstruction of the conjunctival fornices. Ophthalmology 2003; 110: 93-100.

25 Barabino S, Rolando M, Bentivoglio G, Mingari C, Zanardi $\mathrm{S}$, Bellomo R et al. Role of amniotic membrane transplantation for conjunctival reconstruction in ocularcicatricial pemphigoid. Ophthalmology 2003; 110: 474-480.

26 Kheirkhah A, Johnson DA, Paranjpe DR, Raju VK, Casas V, Tseng SC. Temporary sutureless amniotic membrane patch for acute alkaline burns. Arch Ophthalmol 2008; 126: 1059-1066.

27 Maharajan VS, Shanmuganathan V, Currie A, Hopkinson A, Powell-Richards A, Dua HS. Amniotic membrane transplantation for ocular surface reconstruction: indications and outcomes. Clin Experiment Ophthalmol 2007; 35: $140-147$.

28 Fujishima H, Shimazaki J, Shinozaki N, Tsubota K. Trabeculectomy with the use of amniotic membrane for uncontrollable glaucoma. Ophthalmic Surg Lasers 1998; 29: 428-433.

29 Nagai-Kusuhara A, Nakamura M, Fujioka M, Negi A. Long-term results of amniotic membrane transplantationassisted bleb revision for leaking blebs. Graefes Arch Clin Exp Ophthalmol 2008; 246: 567-571.

30 Budenz DL, Barton K, Tseng SC. Amniotic membrane transplantation for repair of leaking glaucoma filtering blebs. Am J Ophthalmol 2000; 130: 580-588.

31 Ainsworth G, Rotchford A, Dua HS, King AJ. A novel use of amniotic membrane in the management of tube exposure following glaucoma tube shunt surgery. Br J Ophthalmol 2006; 90: 417-419.

32 Poonyathalang A, Preechawat P, Pomsathit J, Mahaisaviriya P. Reconstruction of contracted eye socket with amniotic membrane graft. Ophthal Plast Reconstr Surg 2005; 21: 359-362.

33 Finger PT. Finger's amniotic membrane buffer technique: protecting the cornea during radiation plaque therapy. Arch Ophthalmol 2008; 126: 531-534.

34 Eliezer RN, Kasahara N, Caixeta-Umbelino C, Pinheiro RK, Mandia Jr C, Malta RF. Use of amniotic membrane in trabeculectomy for the treatment of glaucoma: a pilot study. Arq Bras Oftalmol 2006; 69: 309-312.

35 Sheha H, Kheirkhah A, Taha H. Amniotic membrane transplantation in trabeculectomy with mitomycin $\mathrm{C}$ for refractory glaucoma. J Glaucoma 2008; 17: 303-307.

36 Budenz DL, Barton K, Tseng SC. Amniotic membrane transplantation for repair of leaking glaucoma filtering blebs. Am J Ophthalmol 2000; 130: 580-588. 
37 Rauscher FM, Barton K, Budenz DL, Feuer WJ, Tseng SC. Long-term outcomes of amniotic membrane transplantation for repair of leaking glaucoma filtering blebs. Am J Ophthalmol 2007; 143: 1052-1054.

38 Liu Y, Li H, Chen J. Shunt tube implantation combining amniotic membrane transplantation and implantation of Molteno implant for glaucoma after penetrating keratoplasty. Yan Ke Xue Bao 2000; 16: 65-72.

39 Luanratanakorn P, Ratanapakorn T, Suwan-Apichon O, Chuck RS. Randomised controlled study of conjunctival autograft $v s$ amniotic membrane graft in pterygium excision. Br J Ophthalmol 2006; 90: 1476-1480.

40 Tananuvat N, Martin T. The results of amniotic membrane transplantation for primary pterygium compared with conjunctival autograft. Cornea 2004; 23: 458-463.

41 Küçükerdönmez C, Akova YA, Altinörs DD. Comparison of conjunctival autograft with amniotic membrane transplantation for pterygium surgery: surgical and cosmetic outcome. Cornea 2007; 26: 407-413.

42 Li Z, Lin YS, Guo H, Li DM, Du YM, Zhang HY. Effect of recombinant epidermal growth factor on ocular surface re-epithelization following amniotic membrane transplantation in patients with pterygium excision. Di Y $i$ Jun Yi Da Xue Xue Bao 2002; 22: 437-438.

43 Tamhane A, Vajpayee RB, Biswas NR, Pandey RM, Sharma $\mathrm{N}$, Titiyal JS et al. Evaluation of amniotic membrane transplantation as an adjunct to medical therapy as compared with medical therapy alone in acute ocular burns. Ophthalmology 2005; 112: 1963-1969.

44 Hopkinson A, McIntosh RS, Tighe PJ, James DK, Dua HS. Amniotic membrane for ocular surface reconstruction: donor variations and the effect of handling on TGF-beta content. Invest Ophthalmol Vis Sci 2006; 47: 4316-4322.

45 Khokhar S, Natung T, Sony P, Sharma N, Agarwal N, Vajpayee RB. Amniotic membrane transplantation in refractory neurotrophic corneal ulcers: a randomized, controlled clinical trial. Cornea 2005; 24: 654-660.

46 Kumar S, Sugandhi P, Arora R, Pandey PK. Amniotic membrane transplantation $v s$ mucous membrane grafting in anophthalmic contracted socket. Orbit 2006; 25: 195-203.

47 Jean-Jacques Gicquel JJ, Dua HS, Brodie A et al. Epidermal growth factor variations in amniotic membrane used for ex-vivo tissue constructs. Tissue Engineering (in press). 